\title{
Expanded polytetrafluoroethylene valved conduit and patch with bulging sinuses in right ventricular outflow tract reconstruction
}

Takako Miyazaki, MD, ${ }^{\text {a }}$ Masaaki Yamagishi, MD, PhD, ${ }^{\text {a }}$ Atsuhiro Nakashima, MD, ${ }^{\text {b }}$ Kouji Fukae, MD, ${ }^{\text {b }}$ Toshihide Nakano, MD, ${ }^{\mathrm{b}}$ Hitoshi Yaku, MD, PhD, ${ }^{\mathrm{a}}$ and Hideaki Kado, $\mathrm{MD}^{\mathrm{b}}$

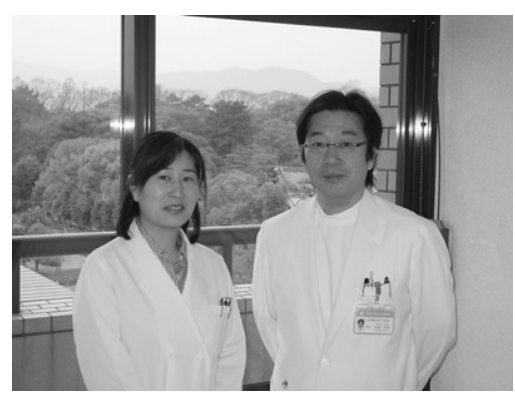

Drs Miyazaki and Yamagishi (left to right)
From the Department of Pediatric Cardiovascular Surgery, Children's Research Hospital, Kyoto Prefectural University of Medicine, ${ }^{a}$ Hirokoji, Kamigyo-ku, Kyoto, Japan; and Department of Cardiovascular Surgery, Fukuoka Children's Hospital, Chuo-ku, Fukuoka, Japan.

Received for publication Jan 14, 2007; revisions received March 13, 2007; accepted for publication March 22, 2007.

Address for reprints: Masaaki Yamagishi, MD, PhD, Department of Pediatric Cardiovascular Surgery, Children's Research Hospital, Kyoto Prefectural University of Medicine, 465 Kajii-cho, Kawaramachi, Hirokoji, Kamigyo-ku, Kyoto, 602-8566, Japan (E-mail: myama@koto.kpu-m.ac.jp).

J Thorac Cardiovasc Surg 2007;134:327-32

$0022-5223 / \$ 32.00$

Copyright (c) 2007 by The American Association for Thoracic Surgery

doi:10.1016/j.jtcvs.2007.03.030
Objectives: No specific prosthetic material is currently recognized as being the most suitable for right ventricular outflow tract reconstruction for congenital heart defects. Prosthetic valves are subject to wear and stress because they do not create vortex flow, which helps natural valves to close. We designed a fan-shaped expanded polytetrafluoroethylene valved conduit and patch with bulging sinuses that create vortex flow, making them more reliable over the long term.

Methods: Bulging sinuses were formed on a sheet of expanded polytetrafluoroethylene using a specially designed mold. Fan-shaped expanded polytetrafluoroethylene sheets $(0.1 \mathrm{~mm}$ thick) were anastomosed to the edge of the bulging sinuses as valve leaflets, creating monocuspid, bicuspid, or tricuspid valves. These valves were implanted in 157 patients undergoing right ventricular outflow tract reconstruction (age 16 days to 45.4 years, median 2.0 years), in 48 patients as a conduit, and in 109 patients as a patch. Valve function was followed up by echocardiography for 5.6 to 63.7 months (mean 20.8 months).

Results: There was no mortality or morbidity, and no patients required reoperation during follow-up. No patients had stenosis, and regurgitation was less than mild in all patients with conduits and moderate in 15 patients (13.8\%) with patches, but moderate regurgitation did not further develop during follow-up. Valve motion was fully maintained in all patients.

Conclusions: The expanded polytetrafluoroethylene valved conduits and patches with bulging sinuses showed excellent early-to-midterm results. The valved conduits and patches seem to be promising alternatives to homografts in right ventricular outflow tract reconstruction. Their function will be followed up further.

$\mathrm{P}$ rosthetic materials are used for right ventricular outflow tract reconstruction (RVOTR) in cases of congenital heart defects with right ventricular outflow hypoplasia or atresia and for pulmonary valve replacement in the Ross procedure. Reliable valves are required to avoid pulmonary regurgitation and consequent right ventricular volume overload. Valved conduits or patches made of various materials have been used to date, ${ }^{1}$ but their long-term availability and durability are unknown or unsatisfactory.

We previously developed a fan-shaped valve made from a 0.1 -mm-thick expanded polytetrafluoroethylene (ePTFE) membrane (Preclude Pericardial Membrane, WL Gore \& Associates, Inc, Flagstaff, Ariz) at the Children's Research Hospital, Kyoto Prefectural University of Medicine in Kyoto, Japan., ${ }^{2,3}$ The valves retain sufficient midterm function, but some eventually become stuck in an open position. ${ }^{4}$ At Fukuoka Children's Hospital in Fukuoka, Japan, we also developed an ePTFE valved conduit that gave excellent early results when implanted during the Ross procedure, ${ }^{5}$ but the long-term results are as yet unknown. We describe an 


\author{
Abbreviations and Acronyms \\ ePTFE = expanded polytetrafluoroethylene \\ RVOTR $=$ right ventricular outflow tract \\ reconstruction
}

improved design of these protheses that should enhance their long-term function. Unlike their predecessors, the new ePTFE valved conduits and patches have bulging sinuses to generate vortex flow similar to that created by the sinus of Valsalva, which helps the native semilunar valves to close. We expect that the vortex flow will help reduce wear and stress, and thus increase the longitivity of the valves.

\section{Materials and Methods}

Expanded Polytetrafluoroethylene Valved Conduit and Patch With Bulging Sinuses

Bulging sinuses are formed on a sheet of ePTFE using stainless steel molds with a pedestal and cover (Figure 1). The pedestal has 3 cavities in its center, $13.5,15,17.5$, or $20 \mathrm{~mm}$ in diameter, depending on the expected diameter of the right ventricular outflow tract. The bottoms of the cavities are interconnected by a small canal linked to a vacuum pump (Figure 2). Mold covers containing 1, 2, or 3 holes are used for making monocuspid, bicuspid, or tricuspid valves, respectively. The ePTFE graft is cut open to make a patch and then placed on the pedestal. One of the covers is placed over the patch and screwed down tightly. Air is pumped out of the cavities, causing the ePTFE patch to bulge into the cavities. The patch is then thermoset by heating at $330^{\circ} \mathrm{C}$ for approximately 15 minutes and cooling for approximately 5 minutes using an industrial dryer to retain the shape of the bulges (sinuses) (Figure 2).

Valve leaflets are made by anastomosing fan-shaped valves made of 0.1-mm-thick ePTFE membrane to the edge of the bulging sinuses

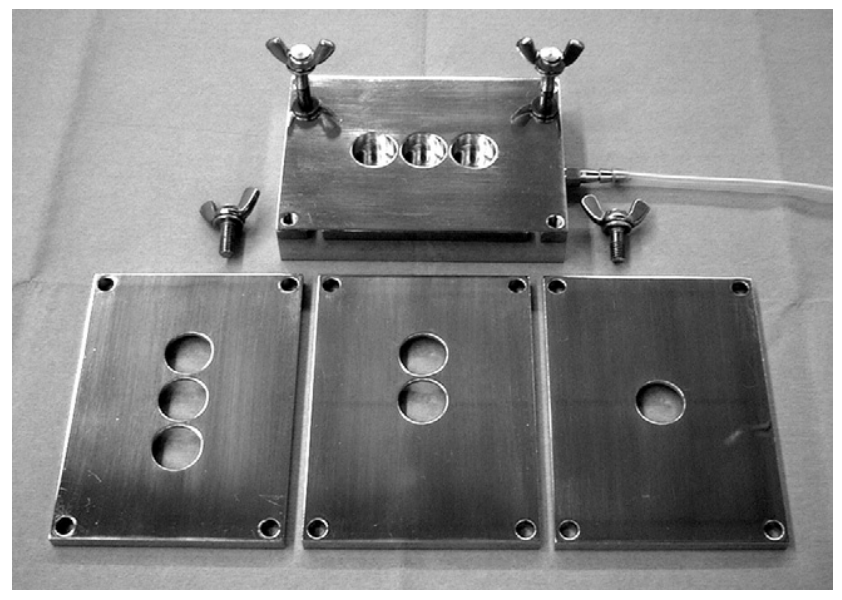

Figure 1. The stainless steel mold used to create the new transannular patch has a pedestal (top) and 3 covers (bottom) containing 1 to 3 holes. using ePTFE running sutures (Figure 3). Knots functioning as nodules of Arantius are made at the center of the free edge of the fan-shaped valves using ePTFE sutures (Figure 3). It takes 20 minutes to fashion the bulging sinuses and approximately 1 hour to cut fan-shaped valves from ePTFE sheets and anastomose them, totaling approximately 1.5 hours to create 1 prosthesis. We make a range of patches, varying in size and number of sinuses. We sterilize them before the operation and at the time of operation choose the one with the most appropriate size for the right ventricular outflow tract. Patches with tricuspid or bicuspid valves are rolled up and sutured with ePTFE running sutures to form conduits (Figure 3). During an RVOTR procedure, the conduit or transannular patch is anastomosed between the right ventricle and the pulmonary artery using continuous ePTFE sutures.

\section{Patients}

Between February 2001 and December 2005, 157 patients underwent RVOTR using these valves with bulging sinuses at the Children's Research Hospital, Kyoto Prefectural University of Medicine in Kyoto, and Fukuoka Children's Hospital in Fukuoka, Japan. A valved conduit was implanted in 48 of the patients (group C), and a valved patch was used in 109 patients (group P). Their median age at the time of operation was 6.9 years (3.0 months to 32.8 years) in group $\mathrm{C}$ and 1.5 years (16 days to 45.4 years) in group $\mathrm{P} ; 13$ patients $(27.1 \%)$ in group $\mathrm{C}$ and 68 patients $(62.4 \%)$

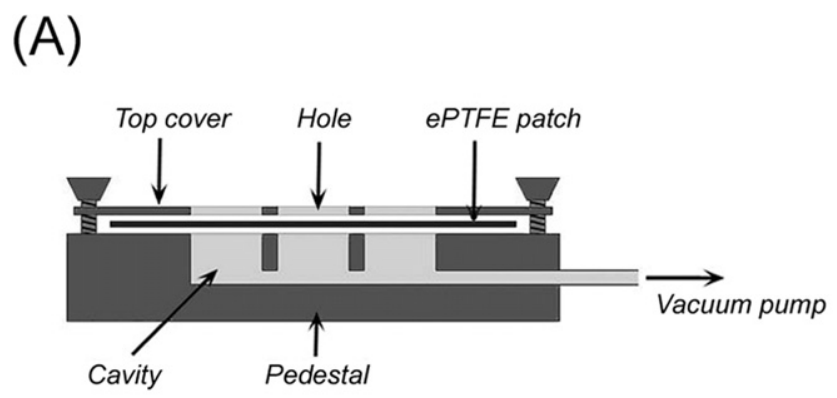

(B)

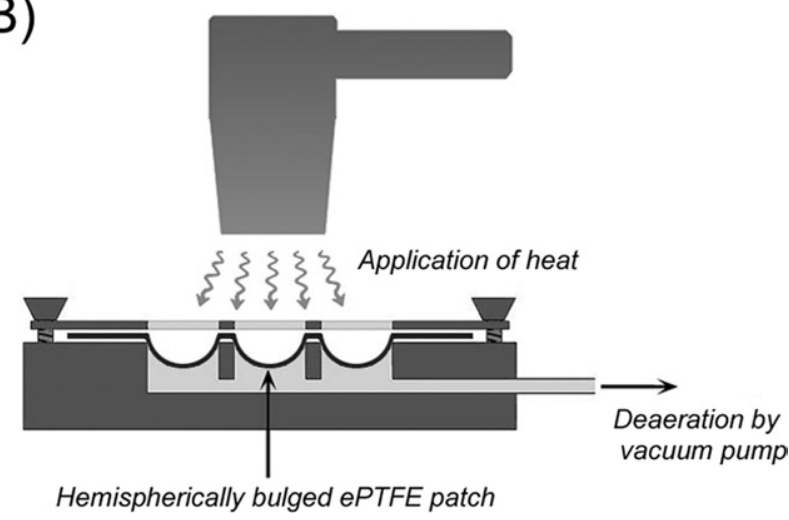

Figure 2. Procedure for creating bulging sinuses in an ePTFE patch. A, ePTFE patch is sandwiched between the cover and the pedestal of the stainless steel mold (lateral view). B, Bulges are created in the ePTFE patch by vacuum suction, which pulls the patch into the cavities in the pedestal of the mold. The shape of the ePTFE is set by heating. ePTFE, Expanded polytetrafluoroethylene. 

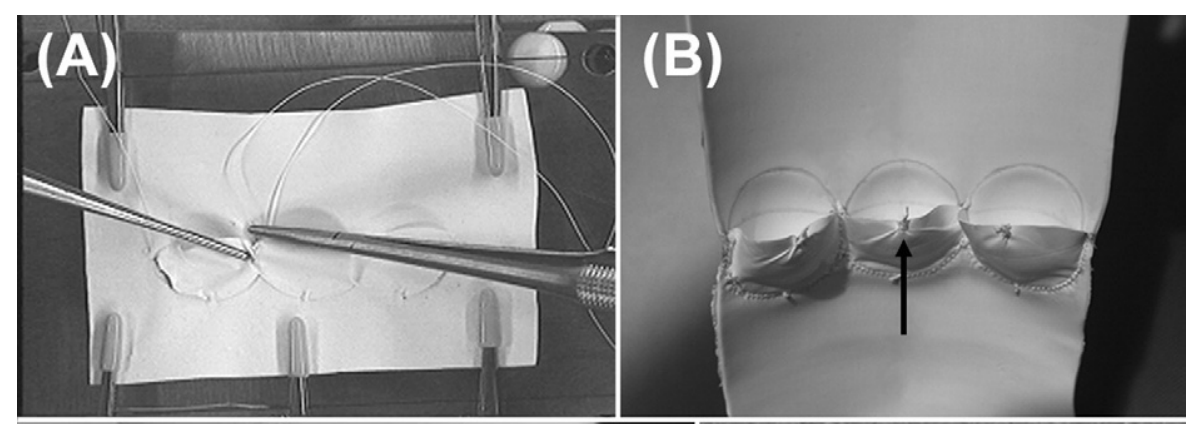

Figure 3. ePTFE patch with 3 sinuses and a tricuspid fan-shaped ePTFE valve. A, Fan-shaped valves were anastomosed to the edge of the bulging sinuses. B, View from inside. Knots functioning as nodules of Arantius were made using ePTFE sutures (black arrow). C, View from outside. D, View from above.

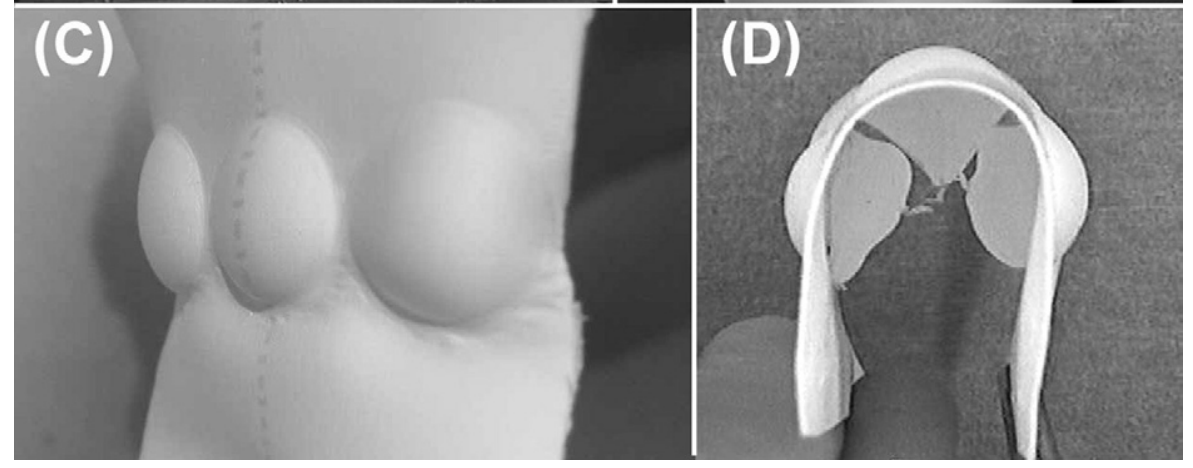

deviation, $20.8 \pm 14.3$ months). The degree of pulmonary regurgitation was classified as none, trivial, mild, moderate, or severe, according to features of the jet flow measured by pulsed Doppler echocardiography. Nineteen patients (39.6\%) in group C and 39

in group $\mathrm{P}$ were aged less than 2 years. Their median (range) body weight at the time of surgery was $20.0 \mathrm{~kg}(5.4-69.0 \mathrm{~kg}$ ) in group $\mathrm{C}$ and $9.0 \mathrm{~kg}(2.9-63.5 \mathrm{~kg})$ in group P. Construction of a continuity between the right ventricle and the pulmonary artery was performed in 29 patients in group $\mathrm{C}$ and in 102 patients in group $\mathrm{P}$, whereas pulmonary replacement was performed in a Ross operation in 19 patients in group $\mathrm{C}$ and in 7 patients in group $\mathrm{P}$. The diagnostic categories are shown in Table 1 . For 12 patients in group $\mathrm{C}$ and 5 patients in group $\mathrm{P}$, the RVOTR was a reoperation, and they received these newly designed protheses as replacements of the other type of valves.

Conduits with tricuspid valves were implanted in 43 patients, and conduits with bicuspid valves were implanted in 5 patients. Figure 4 shows the patients' body weights and the diameters of the conduits. We used bicuspid valves for patients weighing less than $10 \mathrm{~kg}$ because of the difficulty in making sinuses and tricuspid valves that were small enough. The relationship between the diameter of the conduits and the diameter of the sinuses is summarized in Table 2.

Patches with monocuspid, bicuspid, and tricuspid valves were implanted in 89, 18, and 2 patients, respectively. The number of sinuses on the patch was decided according to the size of the autologous tissue used for the posterior wall in RVOTR. In the Ross procedure, it is our new technique to use patches with bicuspid valves and autologous aortic wall with noncoronary cusps. $^{3}$

\section{Follow-up and Data Collection}

To assess the presence of pulmonary regurgitation and to determine the mean blood pressure gradients across the valves, all patients periodically underwent transthoracic 2-dimensional, color flow Doppler echocardiography in the M-mode during follow-up, which ranged from 5.6 months to 5.3 years (mean \pm standard
TABLE 1. Preoperative diagnosis

\begin{tabular}{llcc}
\hline Procedure & \multicolumn{1}{c}{ Diagnosis } & $\begin{array}{c}\text { Conduit } \\
(\mathbf{n}=\mathbf{4 8})\end{array}$ & $\begin{array}{c}\text { Patch } \\
(\mathbf{n}=\mathbf{1 0 9})\end{array}$ \\
\hline $\begin{array}{l}\text { Constraction of } \\
\text { RV-PA continuity }\end{array}$ & & 29 & 102 \\
& TOF + PA & 10 & 6 \\
& TOF + PS & & 56 \\
VSD + PA & 5 & 15 \\
& DORV + PA & 5 & 2 \\
& DORV + PS & 3 & 10 \\
& CTGA + PA & 2 & \\
& CTGA + PS & 2 & 1 \\
& Truncus arteriosus & & 3 \\
& RVOTO & & 4 \\
& Others & 2 & 5 \\
Ross & AS & 19 & 7 \\
& ASR & 12 & 2 \\
& AR & 2 & 2 \\
(Ross mitral) & AVSD & 1 & 3 \\
\hline
\end{tabular}

$R V$, Right ventricle; $P A$, pulmonary atresia; $P S$, pulmonary stenosis; TOF, tetralogy of Fallot; VSD, ventricular septal defect; DORV, double outlet right ventricle; $c-T G A$, collected transposition of the great arteries; $A S$, aortic stenosis; $A S R$, aortic stenosis with regurgitation; $A R$, aortic regurgitation; $R V O T O$, right ventricular outflow tract obstraction; $A V S D$, atrioventriclar septal defect. 


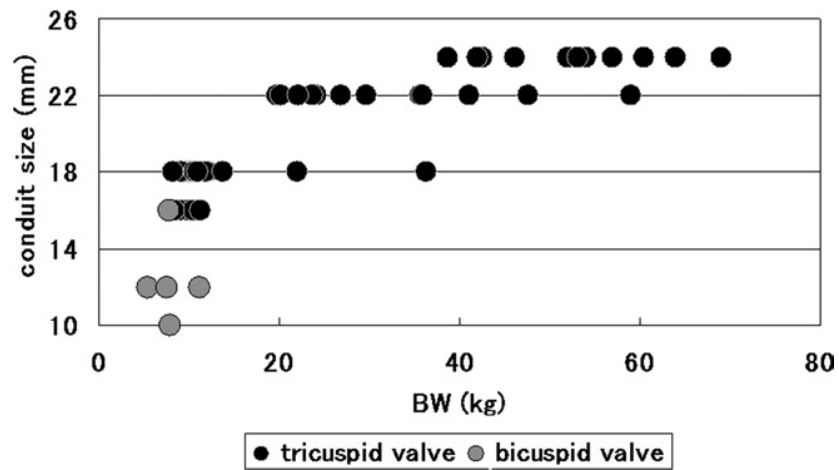

Figure 4. Patients' body weight and diameter of the conduits. BW, Body weight.

patients $(35.8 \%)$ in group $\mathrm{P}$ underwent postoperative cardiac catheterization, and 12 patients in all underwent magnetic resonance angiography. No patients required routine anticoagulation or antiplatelets. Preoperative and postoperative data were collected retrospectively from the patients' medical records. All data are expressed as means \pm standard deviation.

\section{Results}

There was no mortality or morbidity. No patients required reoperation or reintervention. From the most recent echocardiograms, pulmonary regurgitation in group $\mathrm{C}$ was nonexistent in 21 patients (43.8\%), trivial in 17 patients $(35.4 \%)$, mild in 10 patients $(20.8 \%)$, and moderate or severe in 0 patients, whereas in group $\mathrm{P}$ it was nonexistent in 14 patients (12.9\%), trivial in 12 patients $(11.0 \%)$, mild in 68 patients $(62.3 \%)$, moderate in 15 patients $(13.8 \%)$, and severe in 0 patients (Table 3 ). The mean \pm standard deviation peak pressure gradients between the pulmonary artery and the right ventricle were $12.3 \pm 8.7 \mathrm{~mm} \mathrm{Hg}$ (range: 0-31.8 $\mathrm{mm} \mathrm{Hg}$ ) in group $\mathrm{C}$ and $9.8 \pm 11.9 \mathrm{~mm} \mathrm{Hg}$ (range: $0-35 \mathrm{~mm} \mathrm{Hg}$ ) in group P. The gradients were less than 20 $\mathrm{mm} \mathrm{Hg}$ in 38 patients (79.2\%) in group $\mathrm{C}$ and in 77 patients $(70.6 \%)$ in group $\mathrm{P}$ and less than $40 \mathrm{~mm} \mathrm{Hg}$ in all patients (Figure 5). Use of echocardiography, cardiac catheterization, or magnetic resonance angiography demonstrated that

TABLE 2. Relationship between conduit size and sinus size

\begin{tabular}{cccc}
\hline $\begin{array}{c}\text { Conduit size }(\mathbf{m m}) \\
\text { in diameter }\end{array}$ & $\begin{array}{c}\text { Number of } \\
\text { sinuses }\end{array}$ & $\begin{array}{c}\text { Sinus size }(\mathbf{m m}) \\
\text { in diameter }\end{array}$ & $\mathbf{N}=\mathbf{4 8}$ \\
\hline 10 & 2 & 13.5 & 1 \\
12 & 2 & 15 & 3 \\
16 & 2 & 17.5 & 1 \\
& 3 & 13.5 & 7 \\
18 & 3 & 15 & 13 \\
22 & 3 & 17.5 & 12 \\
24 & 3 & 20 & 11 \\
\hline
\end{tabular}

TABLE 3. Pulmonary regurgitation in the most recent echocardiograms

\begin{tabular}{lcc}
\hline Degree & Conduit $\mathbf{n}=\mathbf{4 8}(\%)$ & Patch $\mathbf{n}=\mathbf{1 0 9}(\%)$ \\
\hline Severe & 0 & 0 \\
Moderate & 0 & $15(13.8)$ \\
Mild & $10(20.8)$ & $68(62.3)$ \\
Trivial & $17(35.4)$ & $12(11.0)$ \\
None & $21(43.8)$ & $14(12.9)$ \\
\hline
\end{tabular}

the ePTFE leaflets were functioning well in all patients (Figure 6). No leaflet was completely fixed in the open position, and none had evidence of calcification, thrombus, or peel formation. At the time of writing, all patients are in good clinical condition and none are scheduled for reoperation. One female patient who underwent the Ross delivered a baby 2 years and 8 months after operation.

\section{Discussion}

There is currently no satisfactory material for RVOTR performed for congenital heart defects and the Ross procedure. Even homografts used as valved conduits, which are the most commonly used for RVOTR, suffer from longterm calcification and failure. ${ }^{1,6-11} \mathrm{~A}$ range of materials including autologous pericardiums, porcine pulmonary valves, ${ }^{11-14}$ and bovine jugular veins ${ }^{11,12,15-18}$ have been used, but their long-term availability and durability are unsatisfactory ${ }^{11,12,15,16,18}$ or unknown. A good prosthetic valved conduit or patch that is readily available and has long-term reliability is needed. To date, ePTFE valved conduits and patches have demonstrated the best results. ${ }^{5,19,20}$

The ePTFE membranes used to create artificial heart valves have good biocompatibility, and their microporous structure impedes cellular penetration, thereby making it resistant to calcification that would hinder its mobility. To date, no stenotic lesions have been observed at the site of an ePTFE valve. ${ }^{4,21}$ Fan-shaped ePTFE valves, however, are prone to becoming stuck open, causing pulmonary regurgitation. ${ }^{4}$ They become stuck open because the closure mechanism is inadequate, not because of sclerosis or calcification.

The vortex flow in the sinus of Valsalva plays an important role in the closure of native semilunar valves. ${ }^{22} \mathrm{Be}-$ cause of the lack of the sinus of Valsalva, conventional prosthetic valves, including fan-shaped ePTFE devices, close only passively as a result of backflow. ${ }^{23}$ Therefore, to promote active closure, we designed the new ePTFE conduits and patches with bulging sinuses that provide good vortex flow. In addition, the fan-shaped valve has ePTFE knots functioning as the nodules of Arantius on its central edge.

The ePTFE patches are strong in all directions because of their matrix structure. Our method of creating bulging sinuses in an ePTFE membrane elongates this structure 3 


\section{Conduit}

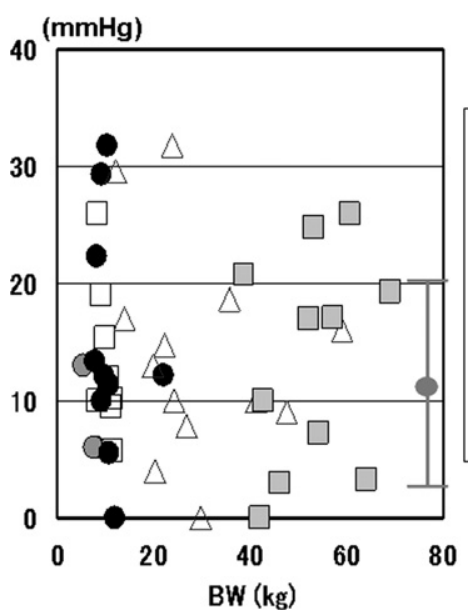

Patch

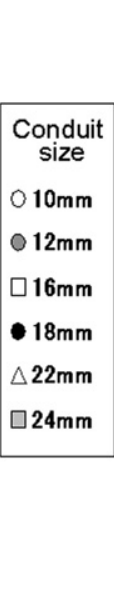

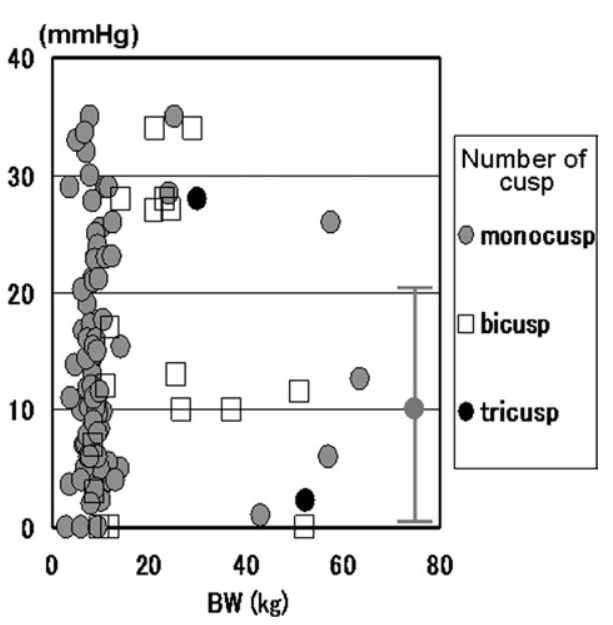

Figure 5. Most recent echocardiogram and cardiocatheterization. Pulmonary regurgitation. Pressure gradients between the right ventricle and the pulmonary artery. $B W$, Body weight. dimensionally. The shape of the sinuses can be thermoset without compromising the strength of the ePTFE.

In our series, the pressure gradients between the right ventricle and the pulmonary artery were high $(>30 \mathrm{~mm} \mathrm{Hg})$ in 2 patients $(4.2 \%)$ in group $\mathrm{C}$ and in 7 patients $(6.4 \%)$ in group $\mathrm{P}$. These pressure gradients, however, occurred between the right ventricle and the pulmonary arteries, not at the level of the pulmonary valves. We believe that the pressure gradients are overestimated in cases in which a patch is used because the turbulence appears just below the valves and might artificially augment the pressure gradients. In the conduits, the pressure gradient occurred at the level of

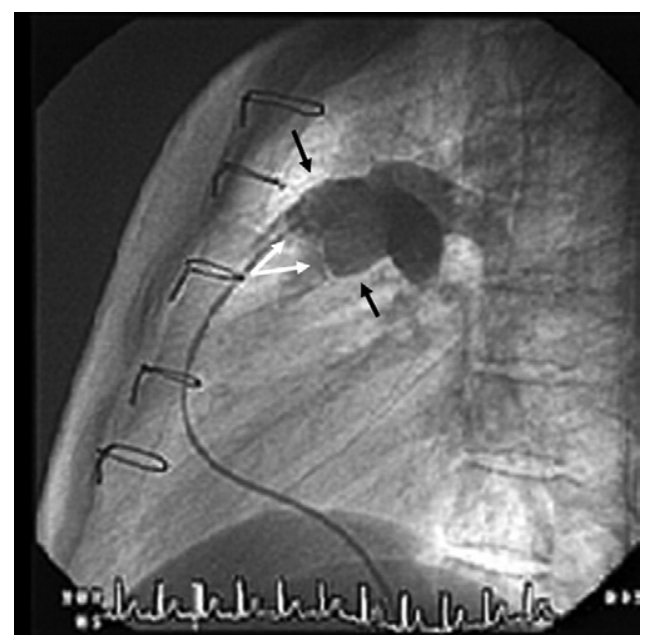

Figure 6. Postoperative pulmonary angiograph of 13.3-year-old, 1.8 years after Ross-Konno operation. The pulmonary regurgitation was nonexistent, and the peak pressure gradient between the right ventricle and the pulmonary artery was $10 \mathrm{~mm} \mathrm{Hg}$. Fan-shaped valves made of 0.1-mm-thick ePTFE membrane (white arrow). Bulging sinus (black arrow). distal anastomosis. In follow-up evaluations, high pressure gradients did not develop further, and we doubt that this would be a significant problem in the future. The level of pulmonary regurgitation is also important, ${ }^{24,25}$ and in our series all patients had less than mild regurgitation, which was satisfactory. In group P, 65 patients had mild regurgitation and 18 patients had moderate regurgitation. This might reflect the quality of the native valve used to construct the posterior wall of the right ventricle outflow tract.

One of the most problematic subgroups of patients, and perhaps the patients who might benefit the most from a combinant pulmonary valve, are those with elevated pulmonary artery pressure and resistance. With regard to patients with pulmonary atresia, 22 of 48 patients with conduit had cardiac catheterization, and 3 patients demonstrated a systolic pulmonary pressure greater than $40 \mathrm{~mm} \mathrm{Hg}$. These 3 patients had major aortopulmonary collateral arteries. Nine of 23 patients with patch insertion had cardiac catheterization, with 3 of them demonstrating greater than 40 $\mathrm{mm} \mathrm{Hg}$ systolic pulmonary pressure. Two of these 3 patients had major aortopulmonary collateral arteries. We believe that the principal risk factor for pulmonary hypertension is the preoperative presence of unobstructed major aortopulmonary collateral arteries, rather than pulmonary atresia per se.

The ePTFE valved conduits and patches with bulging sinuses showed excellent early-to-midterm results. We can make a transannular ePTFE patch with 1 sinus and a monocuspid fan-shaped ePTFE valve that can be used together in cases of tetralogy of Fallot or other congenital cardiac disorders with mild or moderate pulmonary stenosis. A patch with 2 sinuses and a bicuspid valve is useful for augmentation of the narrow pulmonary annulus or reconstruction of the right ventricular outflow tract during the Ross procedure. ${ }^{3}$ In addition, a patch with 3 sinuses and a 
tricuspid valve can be rolled into a cylinder and used to provide an extracardiac conduit between the right ventricle and the pulmonary artery.

Such wide application of a patch or a graft with bulging sinuses and the fan-shaped ePTFE valve is welcomed.

\section{Conclusions}

Although more laboratory and clinical studies are needed to assess the combined effectiveness of the ePTFE graft and patch with sinuses and the fan-shaped ePTFE valve over the long term, our valved conduit or patch seems to be a useful alternative to homografts for RVOTR.

\section{References}

1. Dearani JA, Danielson GK, Puga FJ, Schaff HV, Warnes CW, Driscoll DJ, et al. Late follow-up of 1095 patients undergoing operation for complex congenital heart disease utilizing pulmonary ventricle to pulmonary artery conduits. Ann Thorac Surg. 2003;75:399-411.

2. Yamagishi M, Kurosawa H. Outflow reconstruction of tetralogy of Fallot using a Gore-Tex valve. Ann Thorac Surg. 1993;56:1414-7.

3. Yamagishi M, Emmoto T, Wada Y, Oka T. Pulmonary reconstruction in the Ross procedure: combined autologous aortic and polytetrafluoroethylene valve. J Thorac Cardiovasc Surg. 1998;116:1076-7.

4. Yamagishi M, Kurosawa H, Nomura K, Kitamura N. Fan-shaped expanded polytetrafluoroethylene valve in the pulmonary position. J Cardiovasc Surg (Torino). 2002;43:779-86.

5. Takabayashi S, Kado H, Shiokawa Y, Fukae K, Nakano T. Modified Ross procedure using a conduit with a synthetic valve. Eur J Cardiothorac Surg. 2004;26:1087-91.

6. Tweddell JS, Pelech AN, Frommelt PC, Mussatto KA, Wyman JD, Fedderly RT, et al. Factors affecting longevity of homograft valves used in right ventricular outflow tract reconstruction for congenital heart disease. Circulation. 2000;102(Suppl 3):130-5.

7. Gerestein CG, Takkenberg JJM, Oei FBS, Cromme-Dijkhuis AH, Spitaels SE, van Herwerden LA, et al. Right ventricular outflow tract reconstruction with an allograft conduit. Ann Thorac Surg. 2001;71: 911-8.

8. Bielefeld MR, Bishop DA, Campbell DN, Mitchell MB, Grover FL, Clarke DR. Reoperative homograft right ventricular outflow tract reconstruction. Ann Thorac Surg. 2001;71:482-8.

9. Homann M, Haehnel JC, Mendler N, Paek SU, Holper K, Meisner H, et al. Reconstruction of the RVOT with valved biological conduits: 25 years experience with allografts and xenografts. Eur J Cardiothorac Surg. 2000;17:624-30.

10. Brown JW, Ruzmetov M, Rodefeld MD, Vijay P, Turrentine MW. Right ventricular outflow tract reconstruction with an allograft conduit in non-Ross patients: risk factors for allograft dysfunction and failure. Ann Thorac Surg. 2005;80:655-64.
11. Mohammadi S, Belli E, Martinovic I, Houyel L, Capderou A, Petit J, et al. Surgery for right ventricle to pulmonary artery conduit obstruction: risk factors for further reoperation. Eur J Cardiothorac Surg. 2005;28:217-22.

12. Boethig D, Thies WR, Hecker H, Breymann T. Mid term course after pediatric right ventricular outflow tract reconstruction: a comparison of homografts, porcine xenografts and Contegras. Eur J Cardiothorac Surg. 2005;27:58-66.

13. Kanter KR, Fyfe DA, Mahle WT, Forbess JM, Kirshbom PM. Results with the freestyle porcine aortic root for right ventricular outflow tract reconstruction in children. Ann Thorac Surg. 2003;76:1889-95.

14. Novick WM, Anic D, Lora Solf AL, Arboleda Torres M, Nino De Guzman Leon I, Reid RW, et al. Medtronic Freestyle valve for right ventricular reconstruction in pediatric Ross operations. Ann Thorac Surg. 2004;77:1711-6.

15. Meyns B, Van Garsse L, Boshoff D, Eyskens B, Mertens L, Gewillig $\mathrm{M}$, et al. The Contegra conduit in the right ventricular outflow tract induces supravalvular stenosis. J Thorac Cardiovasc Surg. 2004;128: 834-40.

16. Boudjemline Y, Bonnet D, Massih TA, Agnoletti G, Iserin F, Jaubert F, et al. Use of bovine jugular vein to reconstruct the right ventricular outflow tract: early results. J Thorac Cardiovasc Surg. 2003;126:490-7.

17. Purohit M, Kitchiner D, Pozzi M. Contegra bovine jugular vein right ventricle to pulmonary artery conduit in Ross procedure. Ann Thorac Surg. 2004;77:1707-10.

18. Dave HH, Kadner A, Berger F, Seifert B, Dodge-Khatami A, Bettex D, et al. Early results of the bovine jugular vein graft used for reconstruction of the right ventricular outflow tract. Ann Thorac Surg. 2005;79: 618-24.

19. Koh M, Yagihara T, Uemura H, Kagisaki K, Hagino I, Ishizaka T, et al. Long-term outcome of right ventricular outflow tract reconstruction using a handmade tri-leaflet conduit. Eur J Cardiothorac Surg. 2005;27:807-14

20. Quintessenza JA, Jacobs JP, Morell VO, Giroud JM, Boucek RJ. Initial experience with a bicuspid polytetrafluoroethylene pulmonary valve in 41 children and adults: a new option for right ventricular outflow tract reconstruction. Ann Thorac Surg. 2005;79:924-31.

21. Turrentine MW, McCarthy RP, Vijay P, McConnell KW, Brown JW. PTFE monocusp valve reconstruction of the right ventricular outflow tract. Ann Thorac Surg. 2002;73:871-80.

22. Kunzelman KS, Grande KJ, David TE, Cochran RP, Verrier ED. Aortic root and valve relationships. Impact on surgical repair. J Thorac Cardiovasc Surg. 1994;107:162-70.

23. Ohta Y, Kikuta Y, Shimooka T, Mitamura Y, Yuhta T, Dohi T. Effect of the sinus of Valsalva on the closing motion of bileaflet prosthetic heart valves. Artif Organs. 2000;24:309-12.

24. Borowski A, Ghodsizad A, Litmathe J, Lawrenz W, Schmidt KG, Gams E. Severe pulmonary regurgitation late after total repair of tetralogy of Fallot: surgical considerations. Pediatr Cardiol. 2004;25: 466-71.

25. Bouzas B, Kilner PJ, Gatzoulis MA. Pulmonary regurgitation: not a benign lesion. Eur Heart J. 2005;26:433-9. 